\title{
Embryonic development of the estuarine crab Neosarmatium indicum (Crustacea: Brachyura: Sesarmidae) from the mangroves of the Okinawa Island, Japan
}

\author{
Md. Moniruzzaman Sarker ${ }^{1}$, Md. Sirajul Islam² and Tsuyoshi Uehara ${ }^{3}$ \\ ${ }^{1}$ Department of Zoology, University of Rajshahi, Rajshahi-6206, Bangladesh \\ ${ }^{2}$ Department of Environmental Science and Resource Management, Mawlana Bhashani Science and Technology \\ University, Tangail-1902, Bangladesh. \\ ${ }^{3}$ Department of Chemistry, Biology and Marine Science, Faculty of Science, University of the Ryukyus, 1 Senbaru, \\ Nishihara City, Okinawa 903-0213, Japan
}

\begin{abstract}
The complete embryonic development of the mangrove sesarmid crab Neosarmatium indicum (A. Milne Edwards, 1868) was described based on internal and external morphological changes in live fertilized eggs reared in the laboratory. Several pairs of $N$. indicum were collected from the Nuha River mangrove swamp of the southern Okinawa Island, Japan, which is consisted mainly with the mangrove Kandelia candel, and densely populated by the genus Perisesarma and Neosarmatium indicum. The fertilized eggs were macrolecithal, centrolecithal and spherical in shape, filled with uniform dark olive colour, without evidence of any development. The diameter of fertilized egg was $0.36 \mathrm{~mm}$, which increased to $0.47 \mathrm{~mm}$ before hatching. Embryo development from fertilized eggs to hatching (first zoea stage) lasted average of 16 days at $25^{\circ} \mathrm{C}$ and salinity at $80 \%$. Sixteen stages of embryonic development were categorized by following continuous observation using an optical DIC microscope equipped with digital camera, video camera and printer. After 24 hours of incubation, fertilized eggs became 32-celled stage of development. Before hatching, many chromatophores (mostly black) were evident in the abdominal segments and the telson of embryos. At the end of 16 days incubation, the zoea larvae were successfully hatched out, which were reared in the laboratory conditions for further development.
\end{abstract}

Key words: Neosarmatium indicum, zoea, development, fertilization, mangrove.

\section{Introduction}

Information or documentation dealing with physiology, reproduction and embryology of brachyuran crabs are almost entirely lacking (Garcia-Guerrero \& Hendrickx 2004), where the other groups of decapod crustaceans including the caridean shrimp, marine lobster and river crayfish, have received most of the attention and their embryology is better documented (Clarke et al., 1990, Helluy \& Beltz 1991, Sandeman \& Sandeman 1991, Nazari et al., 2000, Müller et al., 2003, Garcia-Guerrero et al., 2003).

In the brachyuran crabs, females incubate their eggs in the body cavity, which remain attached to the pleopods of abdomen, from spawning to hatching (Guinot 1979, Garcia-Guerrero et al., 2003), and show a great diversity of embryonic development with a significant variation in incubation period and egg diameter (Anderson 1982, Hines 1982, Zimmerman \& Felder 1991, Nagao et al., 1999, Garcia-Guerrero et al. 2003, Garcia-Guerrero \& Hendrickx 2004). The embryology of brachyuran crabs are recent and few species are included from different habitats as hair crab Erimacrus isenbeckii (Atelecyclidae) by Nagao et al., (1999), estuarine or mud crabs Chasmagnathus granulata and Cytograpsus angulatus (Varunidae) by Bas \& Spivak (2000), fiddler crab or mangrove ghost crab Uca lacteal (Ocypodidae) by Yamaguchi (2001), mangrove crabs Ucides cordatus (Ocypodidae) by Pinheiro \& Hattori (2003), Goniopsis pulchra (Grapsidae) and Aratus pisonii (Sesarmidae) by Garcia-Guerrero \& Hendrickx (2004), green shore crab Carcinus maenas (Portunidae) by Chung and Webster (2004) and Hartnoll \& Paul (1982).

However, there is no information available on the embryology of Neosarmatium indicum (A. Milne Edwards, 1868), the most common crab typically associated with mangroves in tropical and subtropical estuaries and coastal lagoons in the Indo-West Pacific, being known from the Bay of Bengal to the Andaman Islands, Sri Lanka, India, Malay Archipelago, the Philippines, Hong Kong, Taiwan, Korea, and Tokyo Bay to Kyushu and the Ryukyu Islands of Japan. This species live in burrow constructed in the edges or within the mangroves or in the reed marsh higher than ordinary high water mark, and among the roots, trunk, and lower branches of mangrove trees. This crab commonly occurred in the mangroves of the Ryukyu Islands, Japan (Islam and Shokita 2000, 2002, Islam et al., 2000). The complete larval development of Perisesarma bidens has been described in detail by Islam and Shokita (2000), although they did not investigate the embryonic development of this species. The objectives of the present study are to provide the detail descriptions of all embryonic stages, and to compare them with those of other species of brachyuran crab.

\section{Materials and Methods}

Several pairs of Neosarmatium indicum were collected by hand during spawning season from the Nuha River mangrove swamp, southern Okinawa Island $\left(26^{\circ} 05^{\prime} \mathrm{N} \sim 26^{\circ} 52^{\prime} \mathrm{N}, \quad 127^{\circ} 40^{\prime} \mathrm{E} \sim 128^{\circ} 16^{\prime} \mathrm{E}\right)$, Japan on 4 June 2005 to June 2006. This swamp is a unique mangrove forest densely populated by Kandelia candel 
and the experimental species. Collected crabs were brought to the Laboratory of Developmental Biology, Faculty of Science, University of the Ryukyus, Okinawa, and maintained in plastic containers. Among them, two pairs were captured during active in courtship behavior, brought to the laboratory separately and reared as paired in plastic containers $(30 \mathrm{~cm} \times 20 \mathrm{~cm} \times 20 \mathrm{~cm})$, filled with filtered seawater, maintained with constant gently aeration, and provided with some rough beach stones as shelter. Photoperiod was kept at $12 \mathrm{~h}$ dark: $12 \mathrm{~h}$ light condition. Water was maintained at $25^{\circ} \mathrm{C}$ and salinity at $28 \%$. The filtered seawater was changed daily until hatching. Freshly fallen brawn leaves of $K$. candel were offered as food to the female daily.

After copulation, fertilization occurred within the female body cavity and the fertilized eggs were extruded within 48 hours, which attached to the pleopods of the female abdomen through the stalk or funiculus and the investment coat. Just after oviposition, a sample of at least 10 eggs from each female was removed every hour up to cleavage and then every 24 hours up to hatching to examine the embryonic development. Development duration is expressed as number of hours/ days after oviposition or spawning of the female. Embryos were described as staging method, adapted for crustacean eggs by Sandeman and Sandeman (1991).

Examination of freshly removed (living) eggs was done using an optical DIC microscope (20x magnification) equipped with digital camera, video camera and a printer (Nikon M-B, 291). Fertilized eggs were placed in $80 \%$ filtered seawater using excavated slides to observe the cleavage, embryo morphology, growth and yolktissues proportion in at least 10 embryos in lateral and frontal views. During examination, shapes, color changes, heartbeat signal and eye formations were also annotated. Diameter of fertilized eggs/ embryos was measured at least 10 embryos to the nearest $0.01 \mathrm{~mm}$ in long axis at 20x magnification with a micrometer objective attached to the microscope. Unfertilized eggs were collected directly from the ovary by sacrificing the female to observe their maturation and to compare with fertilized eggs only. After hatching, the larvae were reared under laboratory conditions up to first crab stage, which datum was not included in this manuscript. Specimens of the female $N$. indicum and the embryos have been deposited in the Laboratory of Developmental Biology, University of the Ryukyus, Okinawa, Japan.

\section{Results}

The copulation period of $N$. indicum was 5-7 hours. After copulation, fertilization occurred within the female body cavity and the fertilized eggs were extruded within 48 hours, which attached to the pleopods of the female abdomen through the stalk or funiculus and the investment coat, encased. Copulated females were observed successfully from spawning to hatching. Developmental stages, average diameter (long axis) and incubation periods of fertilized eggs/ embryos are presented in Table 1. Embryonic development of $N$. indicum was completed within 16 days of incubation. A chronology of embryological events was took place at constant room temperature of $25^{\circ} \mathrm{C}$.

Table 1. Developmental stages, average diameter and incubation period of the fertilized egg/embryos of Neosarmatium indicum (A. Milne Edwards) from spawning to hatching at $25^{\circ} \mathrm{C}$ and $28 \%$ salinity.

\begin{tabular}{|c|c|c|}
\hline Development stages & $\begin{array}{c}\text { Size in diameter } \\
(\mu \mathrm{m}) \\
(\text { Mean } \pm \mathrm{SD}, \mathrm{N}=10)\end{array}$ & $\begin{array}{l}\text { Durations/ } \\
\text { incubation } \\
\text { period }\end{array}$ \\
\hline $\begin{array}{l}\text { Fertilized egg } \\
\text { Stage-1 (Fig. 1A-B) }\end{array}$ & $368.76 \pm 8.48$ & $2-10 \mathrm{~h}$ \\
\hline $\begin{array}{l}\text { Cleavage } \\
\text { Stage-2 (Fig. 1C-G) }\end{array}$ & $370.21 \pm 8.12$ & $12-17 \mathrm{~h}$ \\
\hline $\begin{array}{l}\text { Blastula } \\
\text { Stage-3 (Fig. 1H) }\end{array}$ & $375.37 \pm 9.30$ & $18-40 \mathrm{~h}$ \\
\hline $\begin{array}{l}\text { Gastrula } \\
\text { Stage-4 (Fig. 1I) }\end{array}$ & $377.71 \pm 9.32$ & $41-60 \mathrm{~h}$ \\
\hline $\begin{array}{l}\text { Developing embryos } \\
\text { Stage-5 (Fig. 1J-K) }\end{array}$ & $384.25 \pm 8.51$ & $3-4 d$ \\
\hline $\begin{array}{l}\text { Stage-6 (Fig. 1L) } \\
\text { Stage-7 (Fig. 2A) }\end{array}$ & $\begin{array}{l}388.18 \pm 8.31 \\
391.21 \pm 6.97\end{array}$ & $\begin{array}{l}5 d \\
6 d\end{array}$ \\
\hline Stage-8 (Fig. 2B-C) & $395.07 \pm 6.88$ & $7 d$ \\
\hline Stage-9 (Fig. 2D-E) & $401.17 \pm 5.39$ & $8-9 d$ \\
\hline Stage-10 (Fig. 2F) & $405.43 \pm 6.79$ & $10 d$ \\
\hline Stage-11 (Fig. 2G) & $420.33 \pm 7.12$ & $11 \mathrm{~d}$ \\
\hline Stage-12 (Fig. 2H) & $427.72 \pm 8.01$ & $12-13 d$ \\
\hline Stage-13 (Fig. 2I) & $444.31 \pm 8.22$ & $14 \mathrm{~d}$ \\
\hline Stage-14 (Fig. 2J) & $459.25 \pm 7.42$ & $15 d$ \\
\hline $\begin{array}{l}\text { Before hatching } \\
\text { Stage-15 (Fig. 2K) }\end{array}$ & $471.29 \pm 8.19$ & $16 \mathrm{~d}$ \\
\hline $\begin{array}{l}\text { Hatching } \\
\text { Stage- Zoea (Fig. 2N-O) }\end{array}$ & $1021.91 \pm 7.17$ & $17 \mathrm{~d}$ \\
\hline
\end{tabular}

\section{Descriptions}

\section{Fertilized egg}

Stage-1 (2-10 hours of incubation, Fig. 1A-B): Before cleavage, the fertilized eggs were macrolecithal, centrolecithal and spherical in shape, and filled with a uniform dark olive colour, without evidence of any development (Fig.1A). No polar bodies were observed in eggs examined immediately after they have been laid/ spawned (Fig.1B). Three distinct egg membranes were observed immediate after egg shifted in to the pleopods. The first polar body like structure was extruded out from the zygote after one hour of incubation. At that time the yolk components were yellowish in colour (Fig.1B).

\section{Cleavage}

Stage-2 (12-17 hours of incubation, Fig.1C-G): The first cleavage/ division occurred within 11-12 hours of incubation. The cleavage was holoblastic and characterized by early occurrence of cleavage cavity. At the 2-celled stage, a wide cavity or cleavage furrow was 
formed between the blastomeres (Fig. 1C). The first division was typical, passed through the animal vegetal pole, although it might be inclined due to absorbed of first polar body, which ultimately gave rise to a longer blastomere. The 2-celled embryos under went the second equal division of cleavage within the next hour and the embryos reached at 4-celled stage producing four large blastomeres (Fig. 1D). At the end of 14 hours of incubation, the 4-celled embryos underwent to the third cleavage and reached at 8-celled stage (Fig.1E). By the fourth cleavage, developing 8-celled embryos reached at 16-celled stage after the end of fifteen hours of incubation (Fig. 1F). The fourth cleaved embryos usually underwent fifth cleavage within 16-17 hours of incubation (Fig. 1G). Due to the density of blastomeres, the later stage of cleavage could not be detected clearly.
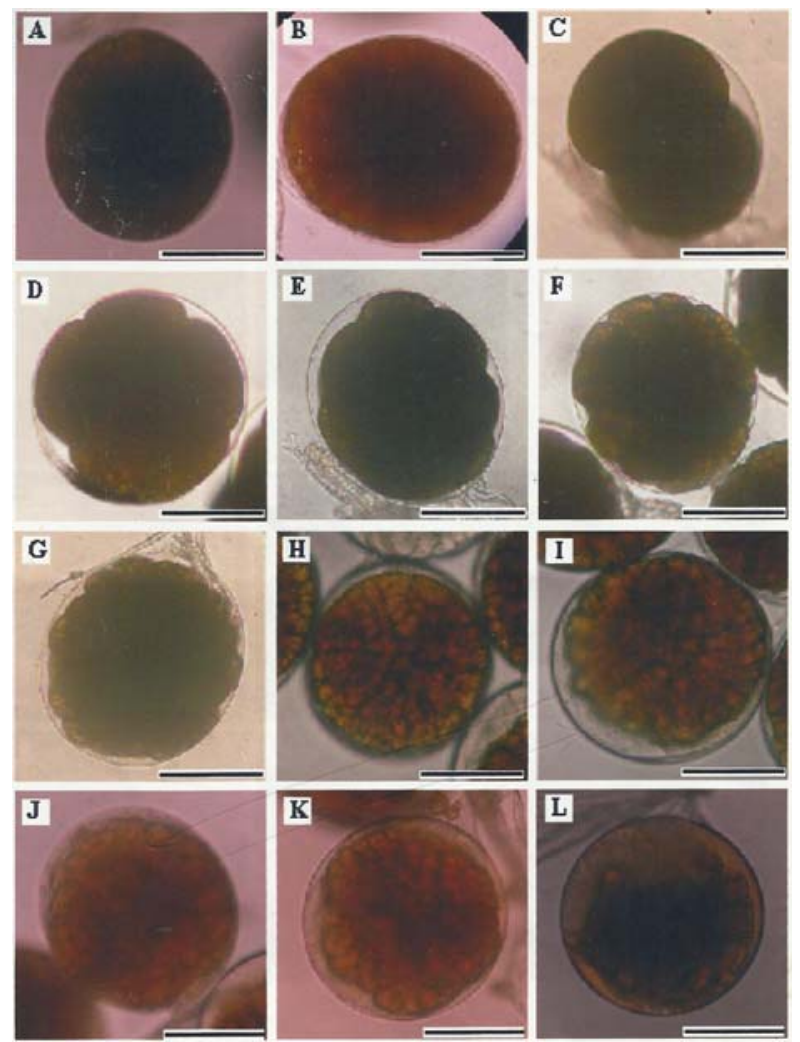

Fig.1. Stages of development in embryos of Neosarmatium indicum (A. Milne Edwards). A, unfertilized egg; B, Stage-1 (fertilized eggs before cleavage); C, Stage-2 (cleavage: C, 2-cell; D, 4cell; E, 8-cell; F, 16-cell; G, 32-cell stage); H, Stage-3 (Blastula); I, Stage-4 (Gastrula); J-K, Stage-5 (developing embryos); L, Stage-6. Scale bars $=100 \mu \mathrm{m}$.

\section{Blastula}

Stage-3 (18-40 hours of incubation, Fig. $1 \mathrm{H})$ : The blastula stage and advanced blastula stage of development is impossible to distinguish individual cells after 18-40 hours of incubation. In these stages, the outer appearances of developing embryos are very similar to that of undivided or un-cleaved fertilized eggs.

\section{Gastrula}

Stage-4 (41-48 hours of incubation, Fig. I: After 41-48 hours of incubation period, the developing embryos reached at the gastrula stage (Fig.1 I).

\section{Developing embryos}

Stage-5 (3-4 days of incubation, Fig. 1J-K): Yolk droplets are somewhat larger and with a lighter yellowish color at the beginning of three days of incubation period (Fig1J). Yolk free portion was first observed at the end of four days of incubation. Evidence of tissues was observed in yolk free portion (Fig. 1K).

Stage-6 (5 days of incubation, Fig.1L): Yolk droplets were larger and more distinct with yellowish color at the five days of incubation period. Yolk free portion was increased in size. Any special organ was not observed.

Stage-7 ( 6 days of incubation, Fig. 2A): At the six days of incubation period, further increase of yolk free portion was observed. Evidence of tissue was more distinct and clear of the yolk free portion.
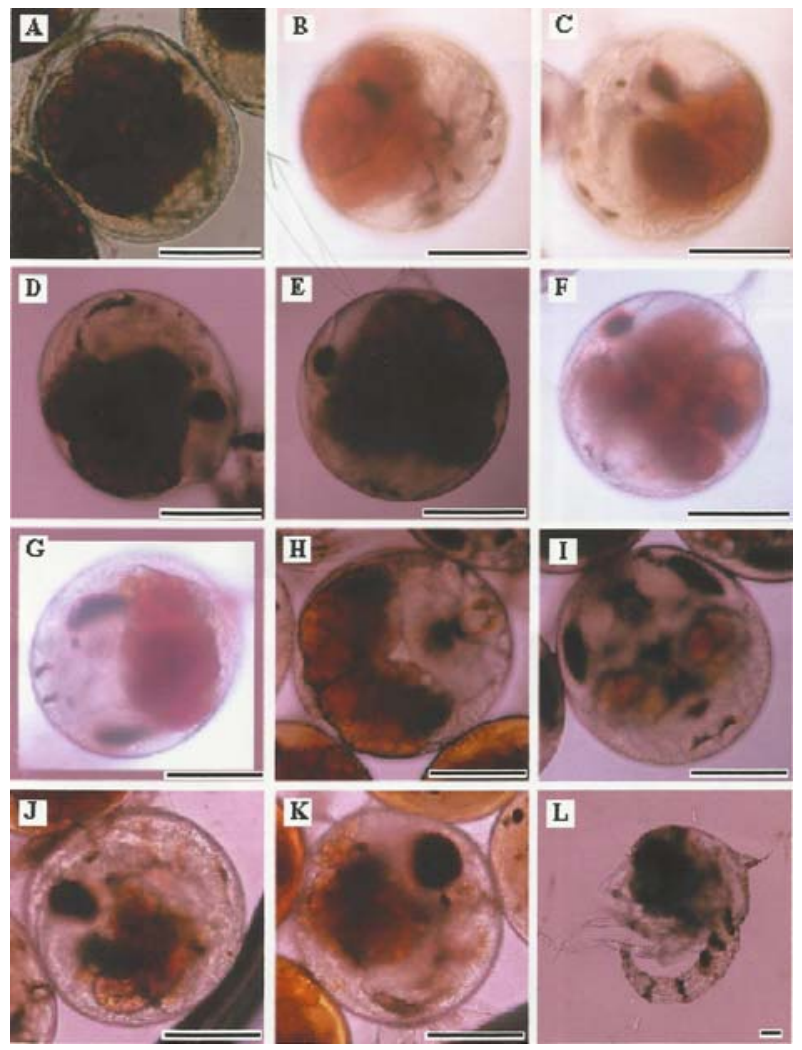

Fig. 2. Stages of development in embryos of Neosarmatium indicum (A. Milne Edwards). A, Stage-7; B-C, Stage-8; C, Stage-8; D, Stage-9; F, Stage-10; G, Stage-11; H, Stage-12; I, Stage-13; J, Stage-14; K, Stage-15; M, (embryo ready to hatch); L, zoeal stage. Scale bars $=100 \mu \mathrm{m}$. 
Stage-8 (7 days of incubation, Fig. 2B-C): First evidence of organs was visible in ventro- lateral position of the yolk free portion at the 7 days of incubation period. Ocular, thoracic-abdominal, and cephalic portion of papilla were observed.

Stage-9 (8-9 days of incubation, Fig. 2D-E): At the eight days of incubation, eyes like organ was first visible (Fig. 2D), and at the end of nine days developing eyes was increased in size (Fig. 2E). No evidence of heart and it beat was observed in this stage.

Stage-10 (10 days of incubation, Fig. 2F): At the ten days of incubation, heart like structure with a little beat jerking was observed first. Eyes were going to more or less complete in size.

Stage-11 (11 days of incubation, Fig. 2G): At this stage, yolk components arranged in four lobes. Developing heart and it beating was observed. Eyes development were incomplete.

Stage-12 (12-13 days of incubation, Fig. 2H): The appearance of eyes was more visible (Fig. $2 \mathrm{H}$ ). Further reduction of yolk granule, looks like two lobes. Heart beating was faster than previous stage.

Stage-13 (14 days of incubation, Fig. 21): Embryos occupied half volume with ventral position. Heart was formed in complete shape and beating fast. Eyes were larger in size, and the cornea was forming and eye pigmentation like retina was more intense. Antennae and mandible was comparatively more developed.

Stage-14 (15 days of incubation, Fig. 2J): About 3/4 of yolk granule was consumed, and the remaining yolk was divided into three patches. Embryos were grown considerably and occupied the entire egg volume except reserve yolk. The heart was dorsal position and the beats were regular. Ocular lobes were final position, and eyes were larger and more complex. All appendages were larger, incompletely segmented, and developing setae. First evidence of rostral spine was traced.

\section{Before hatching}

Stage-15 (16 days of incubation, Fig. 2K): This stage shows an embryo just before hatching. The embryo occupied almost all the available egg volume. Yolk was almost completely depleted, with traces remaining in the cephalothorax cavity. Carapace, maxillipeds and telson were well differentiated. There were many chromatophores, mostly black ones, in the embryo. The egg membrane was transparent, so the pigment cells were easily distinguished under the stereomicroscope. As hatching approached, the embryo frequently moved its abdomen and appendages in the egg membrane. The heartbeat was faster than the previous stage

\section{Hatching}

Stage-First zoea (17 days of incubation period, Fig. $2 \mathrm{~L}$ ): The internal movements of the larvae caused it to rotate $180^{\circ}$, leaving it with the telson and rostral spine facing towards the funiculus. During the hours prior to hatching, the egg dilets as a result of water up take, reached its maximum size.

\section{Discussion}

The embryology of the brachyuran crabs was done haphazardly throughout the world by few researcher. Some of the authors ignored the cleavage, blastula and gastrula stage during development, some started from cleavage or developing embryos. So, meaningful comparison is difficult in this field. Staging of embryos is not standard in the brachyuran crabs. Most of the authors recognized as few as five or less stages (Warner, 1967; Henmi, 1989) and as many as sixteen embryonic stages before hatching (Fukui, 1988, Yamaguchi, 2001). In the present study, seventeen stages were recognized, which is defined by the continuous progress. Undivided (before cleavage) eggs were identified as stage 1 , which is similar to the findings of Kobayashi \& Matsuura (1996), but they recognized 2-celled and 4-celled embryos each as separate stage while 2-celled to 32-celled embryos identified as a single stage in the present study. Yamaguchi (2001) recognized undivided egg to 32celled embryos as a single stage, which is quit different from the present study. Undivided (just spawned or fertilized) eggs are characteristically different from the cleaved one, must be separated as stage 1 , which is more appropriate in the embryology of the brachyuran crabs. Garcia-Guerrero \& Hendrickx (2004) applied the term period instead of stage based on the morphological differences but they ignored the cleavage, blastula and gastrula stage, which is not appropriate in the embryology of brachyuran crabs.

There is a relationship between the incubation period and the temperature (Wear, 1974). Incubation period depends on species and temperature (Yamaguchi, 2001). Under low temperature, the incubation period much extended and vice-versa in higher temperature (Yamaguchi, 2001). Daily or continuous progress of development is very useful where the length of the incubation period is assumed to be proportional to that of each stage (Kobayashi \& Matsuura, 1996). It is possible to estimate the days needed to develop the stages shown in the present study when the total length of the incubation period is known.

In the present species, the largest diameter of the undivided (just fertilized not cleaved) egg of $N$. indicum is $0.36 \mathrm{~mm}$, which increased to $0.47 \mathrm{~mm}$ before hatching. Yamaguchi (2001) reported that the largest diameter of the undivided egg of Uca lectea is $0.24 \mathrm{~mm}$ and it increased to $0.32 \mathrm{~mm}$ in stages 14 and 15 . Garcia-Guerrero \& Hendrickx (2004) investigated the diameter of egg is 0.57-0.62 mm in Aratus pisonii and $0.60-0.63 \mathrm{~mm}$ in Goniopsis pulchra, which is more larger than those of Yamaguchi's investigation and the present study. Comparison of embryonic stages, egg diameters, and incubation periods and temperatures of four species of mangrove brachyuran crabs are shown in Table 2. The eggs (fertilized to embryos) of $N$. indicum was always spherical, which is the most common shape in brachyuran eggs (Hines, 1982; Nagao et al., 1999; Yamaguchi 2001; Pinheiro \& Hattori, 2003; Garcia-Guerrero \& Hendrickx, 2004). 
Table 2. Comparison of embryonic development of four species of mangrove crabs including $N$. indicum (A. Milne Edwards). References: 1, Garcia-Guerrero and Hendrickx (2004); 2, Present study; 3, Yamaguchi (2001).

\begin{tabular}{lccccc}
\hline \multicolumn{1}{c}{ Family \& Species } & $\begin{array}{c}\text { Embryonic } \\
\text { stages }\end{array}$ & $\begin{array}{c}\text { Incubation } \\
\text { period (days }\end{array}$ & $\begin{array}{c}\text { Diameter of } \\
\text { embryos }(\mathrm{mm})\end{array}$ & $\begin{array}{c}\text { Incubation } \\
\text { temp. }\left({ }^{\circ} \mathrm{C}\right)\end{array}$ & \multicolumn{2}{c}{ References } \\
\hline Grapsidae, Goniopsis pulchra & 9 periods & 15 & $0.60-0.64$ & $26-28$ & 1 \\
Sesarmidae, Aratus pisonii & 8 periods & 14 & $0.57-0.62$ & $26-28$ & 1 \\
N. indicum & 15 & 16 & $0.36-0.47$ & 25 & 2 \\
Ocypodidae, Uca lactea & 15 & 15.4 & $0.24-0.32$ & 28 & 3 \\
\hline
\end{tabular}

The embryonic development of $N$. indicum is similar and matches the general embryonic pattern observed in many brachyuran crabs, including in much larger tropical and subtropical species (Garcia-Guerrero \& Hendrickx, 2004; Pinheiro \& Hattori, 2003) and in cold water species that experience a very slow embryonic development (Nagao et al., 1999). Total incubation period of embryos was 17 days in the present species where it was 14 days in Aratus pisonii and 15 days in Goniopsis pulchra observed by Garcia-Guerrero \& Hendrickx (2004). The development duration of $P$. bidens is little longer that that of $A$. pisonii and $G$. pulchra, although the incubating temperature was similar as in $A$. pisonii and G. pulchra. Just before hatching or the final days of the embryonic development, all features that characterized the first zoeal stage of $N$. indicum was present, when compared with the illustrations of first zoea reported by Islam \& Shokita (2000).

\section{Acknowledgements}

We express our sincere thanks to Mr. Yuji Hiratsuka (Laboratory of Developmental Biology) and Dr. Nabiul Islam Khan (Laboratory of Ecology), Faculty of Science, University of the Ryukyus for their kind assistance to perform the laboratory maintenance and to prepare the early version of this manuscript. The first author is also expressing his sincere gratitude to the JSPS (Japan Society for the Promotion of Science) for financial support during conducting the experiment, as well as preparation, presentation and publication of the manuscript.

\section{References}

Anderson, D. 1982. Embryology in D. Bliss and L. Abele, eds. Embryology, Morphology and Genetics. The Biology of Crustacea. Vol. 2. Pp. 1-36, Academic Press, Cambridge, England.

Bas, C.C. \&, Spivak, E.D. 2000. Effect of salinity on embryos of two southwestern Atlantic estuarine grapsid crab species cultured in vitro. J. Crust. Res. 20: 647-656.

Chung, J.S. \& Webster, S.G. 2004. Expression and release patterns of neuropeptides during embryonic development and hatching of the green shore crab, Carcinus maenas. Development 131: 4751-4761.
Clarke, A., Brown, H. \& Holmes, L. 1990. The biochemical composition of eggs from Macrobrachium rosenbergii in relation to embryonic development. Comp. Biochem. Physiol. A 96: 505-511.

Fukui, Y. 1988. Comparative studies on the life history of the grapsid crabs (Crustacea, Brachyura) inhabiting intertidal cobble and boulder shores. Publs. Seto Mar. Biol. Lab. 33: 121-162.

Garcia-Guerrero, M., Hendrickx, M.E., \& Villarreal, H. 2003. Description of the embryonic development of Cherax quadricarinatus von Martens, 1868 (Decapoda: Parastacidae), based on the staging method. Crustaceana 76: 296-280.

Garcia-Guerrero, M. \& Hendrickx, M.E. 2004. Embryology of decapod crustaceans I. Embryonic Development of the mangrove crabs Goniopsis pulchra and Aratus pisonii (Decapoda: Brachyura). J. Crust. Biol. 24: 666-672.

Guinot, D. 1979. Morphologie et phylogenèse des brachyoures. Mémoires du Muséum national d'Histoire naturelle. Série A Tome 112: 1-353.

Hartnoll, R.G. \& Paul,G.K. 1982. The embryonic development of attached and isolated eggs of Carcinus maenas. Intl. J. Invert. Reprod. 5: 247-252.

Helluy, S. \& Beltz, S. 1991. Embryonic development of the American lobster (Homorus americanus): quantitative staging and characterization of an embryonic molt cycle. Biol. Bull. 180: 355-371.

Hines, A.1982. Allometric constraints and variables of reproductive effort in brachyuran crabs. Mar. Biol. 69: 309320.

Henmi, Y. 1989. Reproductive ecology of three ocypodid crabs I. The influence of activity differences on reproductive traits. Ecol. Res. 4: 17-29.

Islam, M.S. \& Shokita, S. 2000. Larval development of a mangrove rearing crab Perisesarma bidens De Haan (Crustacea: Brachyura: Sesarminae). Bang. J. Fish. Res. 4: 43-56.

Islam, M.S. \& Shokita, S. 2002. Larval survival and morphology of the mangrove dwelling sesarmid crabs in the Okinawa Island of Japan. Fish. Sci. 68: 409-412.

Islam, M.S., Shokita, S. \& Nagai, T. 2000. Effects of salinity on the larval development of the mangrove dwelling semiterrestrial sesarmine crab, Perisesarma bidens (De Haan). Crust. Res. 29: 152-159.

Kobayashi, S. \& Matsuura, S. 1996. Egg development and variation of egg size in the Japanese mitten crab Eriocheir japonicus (De Haan). Benthos Res. 48:29-39. 
Müller, Y., Nazari, E. \& Simões-Costa, M. 2003. Embryonic stages of the freshwater prawn Macrobrachium olfersii (Decapoda, Palaemonidae). J. Crust. Biol. 23: 869-875.

Nagao, J., Munehara, H., \& Shimazaki, K. 1999. Embryonic development of the hair crab Erimacrus isenbeckii. J. Crust. Biol. 19: 77-83.

Nazari, E., Rauh, Y., \& Ammar, D. 2000. Embryonic development of Palaemonetes argentinus (Nobili, 1901) (Decapoda, Palaemonidae), reared in the laboratory. Crustaceana 73: 143-152.

Pinheiro, M. \& Hattori, G. 2003. Embryology of the mangrove crab Ucides cordatus (Brachyura: Ocypodidae). J. Crust. Biol. 23: 729-737.
Sandeman, R, \& Sandeman, R. 1991. Stages in the development of the embryo of the freshwater crayfish Cherax destructor. Roux's Arc. Develop. Biol. 200: 27-37.

Warner, G.F. 1969. The life history of the mangrove tree crab, Aratus pisonii. J. Zool. London 153: 321-335.

Wear, R. 1974. Incubation of British decapod crustacea, and the effects of temperature on the rate and success of embryonic development. J. Mar. Biol. Assoc. 54: 745-762.

Yamaguchi, T. 2001. Incubation of eggs and embryonic development of the fiddler crab, Uca lacteal (Decapoda, Brachyura, Ocypodidae). Crustaceana 74: 449-458.

Zimmerman, T.L. \& Felder, D.L. 1991. Reproductive ecology of an intertidal brachyuran crab, Sesarma sp. (nr. reticulatum), from the Gulf of Mexico. Biol. Bull. 181: 387401. 